Research Article

\title{
Intern's knowledge of clinical pharmacology and therapeutics at Puducherry: a cross-sectional study
}

\author{
Nitya S*, Mangaiarkkarasi A, Meher Ali R, Maruthi Sripathi Sawadkar
}

Department of Pharmacology, Sri Manakula Vinayagar Medical College and Hospital, Puducherry, India

Received: 30 July 2013

Accepted: 4 August 2013

*Correspondence to:

Dr. Nitya S,

Email:

drnityapharm@gmail.com

(C) 2013 Nitya $\mathrm{S}$ et al. This is an open-access article distributed under the terms of the Creative Commons Attribution NonCommercial License, which permits unrestricted noncommercial use, distribution, and reproduction in any medium, provided the original work is properly cited.

\begin{abstract}
Background: Internship is the intermediate period between under-graduation and general practice. The dexterity of health professional relies upon prescribing practices. Clinical pharmacology and therapeutics (CPT) is a crucial discipline for interns to acquire safe and rational prescription of drugs. Cultivating sound knowledge about CPT during under graduation is, henceforth, mandatory.

Aims and objectives:

1. To assess whether the undergraduate CPT teaching and internship training had prepared interns adequately for safe and rational prescription.

2. To assess the awareness and reporting of adverse drug reaction (ADR).
\end{abstract} Methods: 110 interns were enrolled after obtaining informed written consent. A structured questionnaire was given to them including basic demographic information, undergraduate CPT teaching, experience of ADR and any deficiency in the under-graduate CPT teaching.

Results: Response rate was $91 \%$ in which 53 were males and 47 females. 81 considered themselves aware of CPT. 56\% \& 57\% interns were able to prescribe drug safely and rationally respectively. Without supervision, they were confident to prescribe antacids (93\%), vitamins and minerals (90\%), NSAIDS (85\%), antihistamines (82\%), antibiotics (75\%), antiemetics (62\%) and antiasthmatics (52\%). Only $22 \%$ had reported ADR and opined that it could lead to hospitalization $(51 \%)$, prolonged hospital stay (33\%), morbidity $(16 \%)$ and death $(21 \%)$. According to interns, the topics where more emphasis needed were ADR, dosage calculation, pediatric and emergency medicine and therapeutic drug monitoring during undergraduate CPT teaching.

Conclusion: CPT teaching should be improved at undergraduate level for safe and rational prescribing including ADR monitoring, ADR reporting and dosage calculation.

Keywords: Clinical pharmacology and therapeutics, Undergraduate medical education, ADR monitoring, Interns

\section{INTRODUCTION}

The important goal in teaching of undergraduate students in pharmacology is to inculcate a rational and scientific basis of therapeutics. Clinical Pharmacology and Therapeutics (CPT) is a crucial discipline to acquire these competencies. Cultivating sound knowledge about CPT in under graduation and internship is, henceforth, compulsory. Hence the Indian government has progressively integrated CPT into undergraduate curriculum. ${ }^{1}$ Integrated teaching method includes teaching in organ system based manner rather than didactic lectures. The benefits are widely discussed by WHO. ${ }^{2}$
According to Medical Council of India (MCI), under "Regulations of graduate medical education", 1997, Medicinae Baccalaureus, Baccalaureus Chirurgiae (MBBS ) is a certified study extending over four and half academic years divided into nine semesters followed by one year Compulsory Rotatory Residential Internship (CRRI). The period of four and half years is divided into three phases; phase-1 (2semesters) which includes preclinical subjects viz Human Anatomy, Physiology, Biochemistry and introduction to Community Medicine including Humanitics; phase -2 (3 semesters) consisting of Para-clinical / clinical subjects viz Pathology, Pharmacology, Microbiology, Forensic Medicine 
including Toxicology and part of Community Medicine; phase-3 consists of continuation of study of clinical subjects for 7 semesters after passing phase- 1 and the clinical subjects are medicine and its allied specialities, surgery and its allied specialities, Obstetrics and Gynecology and community medicine. No student shall be permitted to join phase-2 group of subjects until passing all the phase- 1 subjects. Overall didactic lectures were allotted one third of time schedule whereas twothird for practical, clinical or/ and group discussion. ${ }^{1}$

According to MCI apart from extensive didactive lectures Pharmacology teaching should prepare undergraduates to be skilled in ability to prescribe drugs for common ailments, recognize adverse drug reaction, interaction of commonly used drugs, observe experiments for the study of effect of drugs, bioassay and interpretation of experimental data, scan information on common pharmaceutical preparation and critical evaluation of drug formulation. MCI also recommends integrated teaching of Pharmacology with clinical and pre-clinical departments. ${ }^{1}$

Unfortunately despite increasing amount of attention being given to enhance good prescribing skills, desired impact is not seen due to deficient CPT teaching during under graduation. The first prescription by the medical students begins during internship. However inadequate CPT training to them have been found to be responsible for significant number of prescribing errors. ${ }^{3-4}$ Several training methods have been proposed to improve CPT at under graduate level. ${ }^{5-6}$ Even a model curriculum was proposed to MCI, India at 2006 to improve CPT. ${ }^{7}$ Apart from these, it is also mandatory to periodically assess the medical students and interns for effective CPT teaching. Several studies had been done on the same discipline to assess CPT across the world. ${ }^{8-9}$ However very few studies were done in India. ${ }^{10}$ Keeping this in view the present study was aimed to assess the intern's knowledge about CPT at Sri Manakula Vinayagar Medical College and Hospital, Pondicherry.

\section{METHODS}

\section{Study place}

The study was conducted at Sri Manakula Vinayagar Medical College and Hospital located at Pondicherry in India. This Institution is approved by the Medical Council of India, Ministry of Health and Family Welfare, Government of India and is affiliated to the Pondicherry University. It is an Ultra-modern multi-specialty tertiary care hospital and a medical research center. The hospital has an inpatient capacity of 900 beds inclusive of 125 critical care beds in different specialities. As a tertiary care hospital, the health care services offered are comprehensive covering investigation, diagnosis, therapy, surgery and post-operative care. The inpatient services are complemented with day centers, outpatient facilities and an exclusive center for health checkup for executives. It teaches both under-graduate and postgraduate students. This study was conducted after obtaining approval from Institutional Ethical Committee.

\section{Development of questionnaire}

It was a descriptive questionnaire-based prospective study. A structured questionnaire modified from the work of Oshikoya et al, was used in the study which included four major categories namely basic demographic information, undergraduate CPT teaching, experience of adverse drug reaction (ADR) and any deficiency in the under-graduate CPT teaching. ${ }^{8}$ There were 22 questions which were mostly yes/ no type or multiple choice type. In multiple choices, more than one choice was allowed to be chosen. Fill in the blank type questions were also included (Annexure 1).

\section{Participants}

The participants were interns of the college from first and supplementary batch. The study was conducted from November 2011 to January 2012. The interns were either in the end or middle of their internship. A total of 110 interns participated in the study. Informed written consent was obtained prior to their participation in the study. The questionnaire was filled on the spot. Confidentiality was assured.

\section{Data analysis}

Data were entered and analyzed using SPSS software (SPSS v16.0). The data were expressed through descriptive statistics.

\section{RESULTS}

Only 100 interns responded back. Out of 100 respondents $53 \%$ were male and $47 \%$ were female out of which $64 \%$ were 22 years old whereas $35 \%$ and $1 \%$ were 23 and 24 years old respectively. $81 \%$ of interns were aware of CPT which was taught during undergraduate period whereas $19 \%$ were not. $56 \%$ of interns were satisfied with undergraduate CPT teaching whereas $44 \%$ were not. Knowledge about CPT during their training period is shown in (Figure 1).

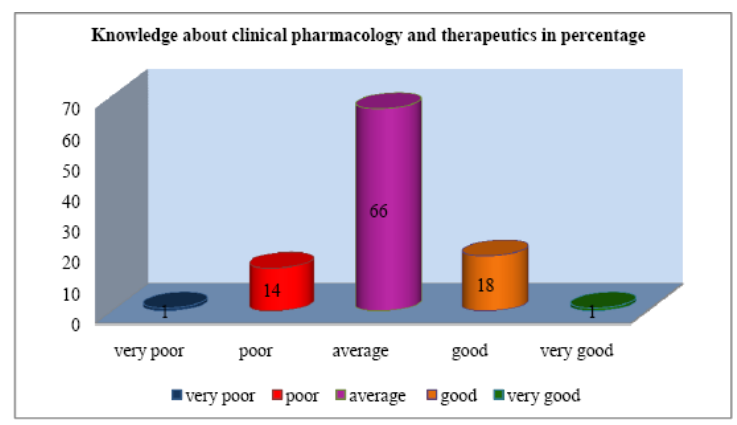

Figure 1: Knowledge about clinical pharmacology and therapeutics in percentage. 
$47 \%$ of interns considered themselves capable of rational prescription, whereas $43 \%$ were not. $67 \%$ of participants had encountered problem while prescribing the drugs during their internship period whereas $33 \%$ were not. The various problems encountered during the internship by the interns while prescribing is shown in (Figure 2). 66\% felt that experience is needed for prescribing; $45 \%$ and $28 \%$ felt that confidence and availability of advice will improve prescribing ability.

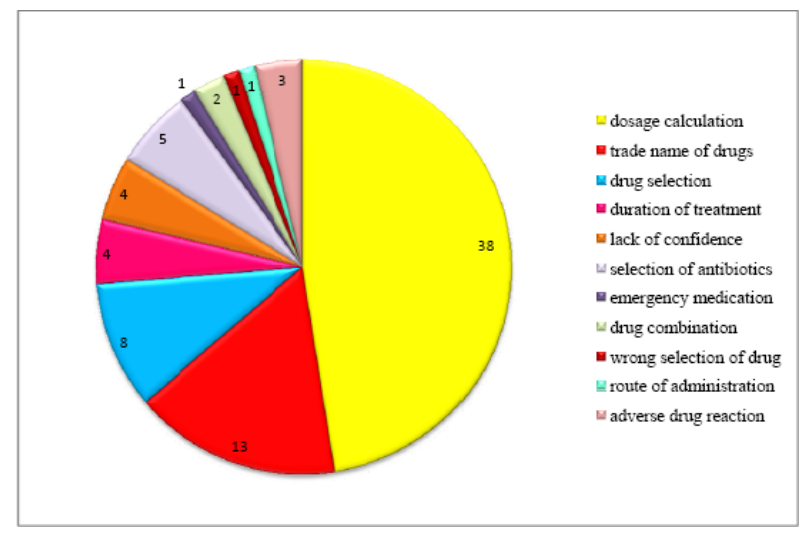

Figure 2: Problems encountered while prescribing during internship represented in percentage.

The various drugs which could be prescribed by the interns without the guidance of senior or faculty member is shown in (Figure 3). Similarly the interns required guidance/ advice from the senior or faculty member while prescribing different groups of drugs for special cases like elderly people, children, pregnant women or people with systemic diseases (renal /liver impairment) is shown in (Figure 4).

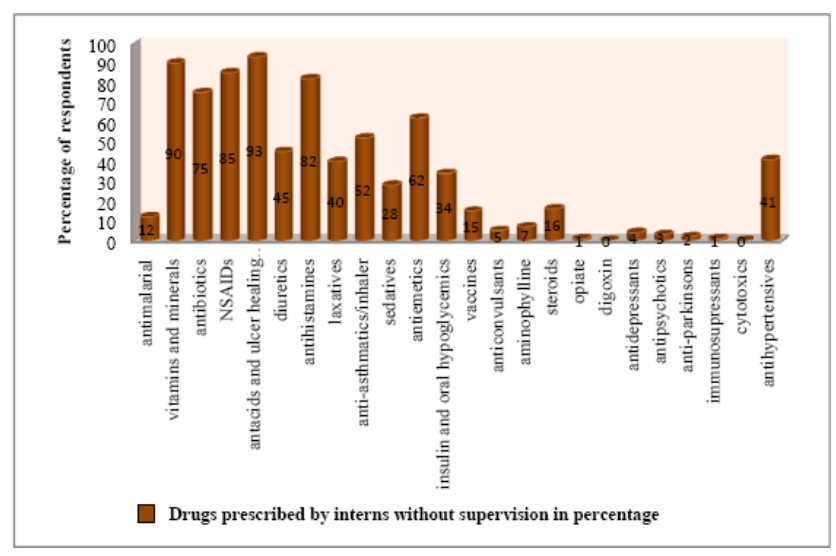

Figure 3: Drugs prescribed by interns without supervision in percentage.

$78 \%$ of the interns felt that while prescribing safety of the drug was very important; $36 \%$ considered efficacy as important; $38 \%$ considered cost as important factor and $8 \%$ of respondents felt that tolerance (or) resistance, age factors, life style factors, patient compliance, adverse drug reaction, age related dosage and combination of drugs should also be considered while prescribing.

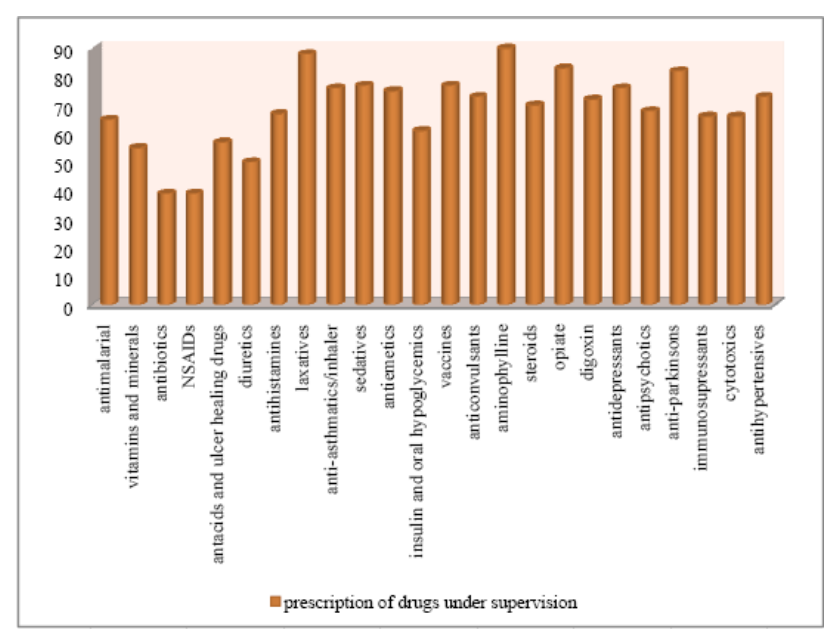

Figure 4: Prescription of drugs under supervision (for special cases) expressed in percentage.

Regarding adverse drug reaction, 96\% of individuals were aware of adverse drug reaction. $49 \%$ had seen different types of adverse drug reaction during their internship period and $51 \%$ had seen during their training period. Figure 5 shows the reasons for adverse drug reaction as suggested by interns.

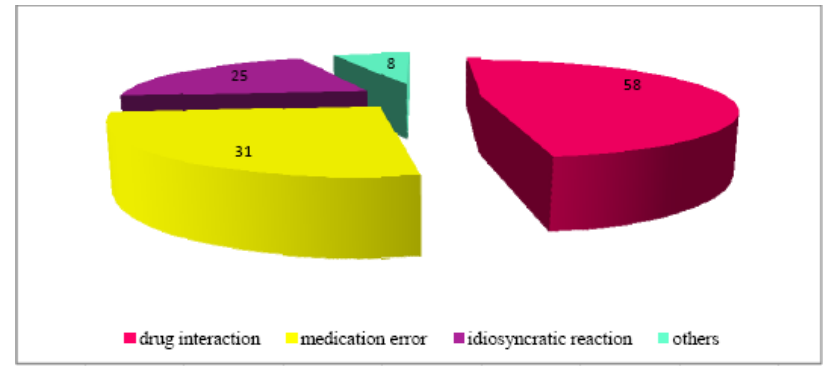

Figure 5: Reasons for adverse drug reaction expressed in percentage.

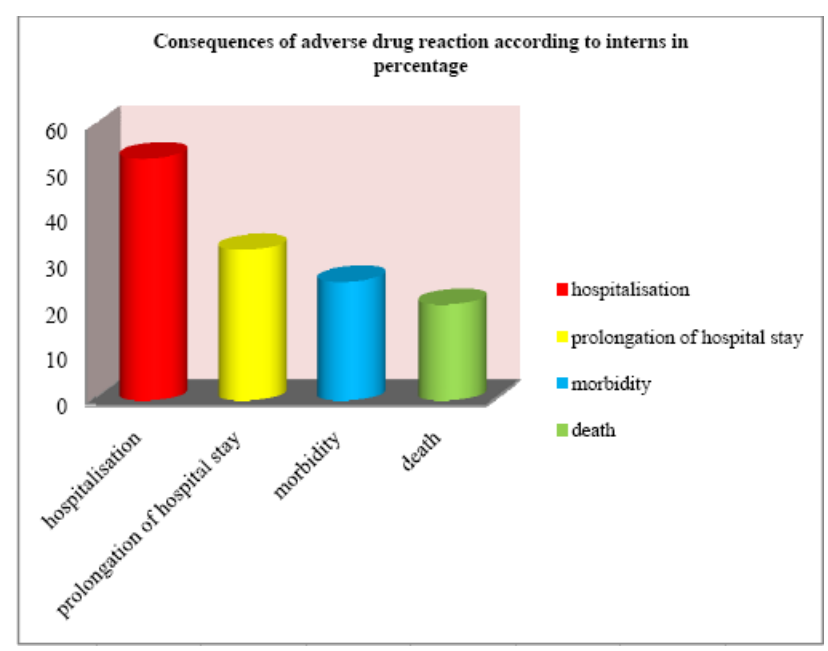

Figure 6: Consequences of adverse drug reaction according to interns in percentage. 
Figure 6 shows the various consequences of adverse drug reaction according to the interns. $88 \%$ interns felt that adverse drug reaction was avoidable or predictable. $89 \%$ considered that adverse drug reaction could be prevented with improved knowledge. Percentage of the interns who reported or not reported adverse drug reaction is shown in Figure 7 . Out of $22 \%$ who reported adverse drug reaction, $21 \%$ had reported it to head of the department, $3 \%$ to national pharmacovigilance Centre, $3 \%$ to senior faculties in the department and $21 \%$ to adverse drug reaction monitoring committee in the hospital.

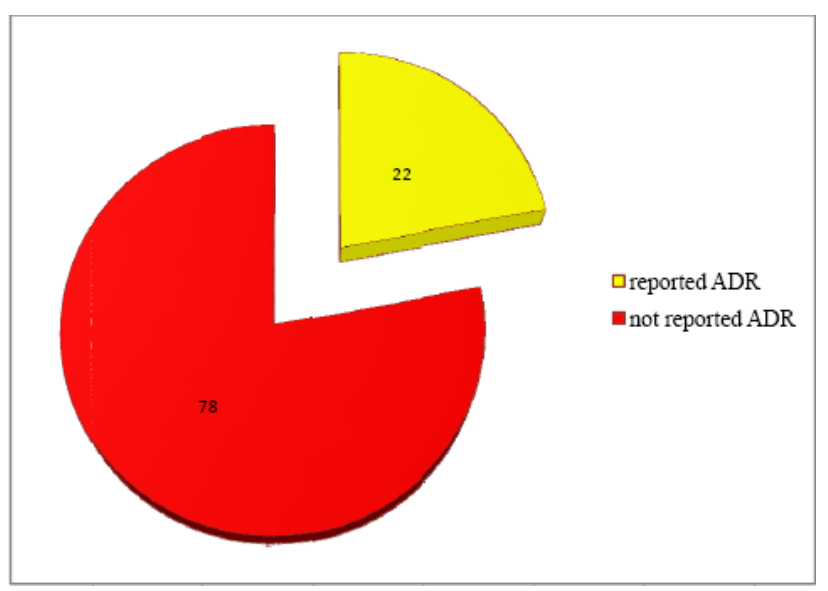

\section{Figure 7: Percentage of interns who reported adverse} drug reaction.

72 interns felt that they would avoid adverse drug reaction using their undergraduate knowledge. Before prescribing the drug, $74 \%$ of the respondents had the habit of checking information about the drug profile and the main sources were CIMS Asia (40\%), text book of Pharmacology- Tripathi (34\%), drug information slip given along with drug $(6 \%)$ and Washington manual $(1 \%)$.

Though majority of respondents had knowledge about adverse drug reaction and its consequences, more than $50 \%$ of the interns felt that CPT training should be improvised in following areas like adverse drug reaction (27\%), dosage (20\%), emergency medication (13\%), pediatric medication $(13 \%)$, therapeutic drug monitoring (9\%), selection of antibiotics (9\%), drug dosage $(7 \%)$, insulin dose calculation (5\%), antihypertensive (4\%), drug interaction (4\%), drug combination (3\%), dosage calculation (2\%), vaccination $(2 \%)$, route of administration $(2 \%)$, poisoning $(2 \%)$, pharmacodynamics of drug $(2 \%)$ and cytotoxic drugs $(1 \%)$.

\section{DISCUSSION}

Gaining knowledge and implementing the same in clinical practice is the integral part of learning medicine. Learning CPT plays an important role in the development of rational and effective prescribing skills by the medical students. In our study majority of the respondents were aware of the CPT and rated their knowledge as average.
However nearly half of the respondents were only satisfied with CPT teaching and feel confident about their rational prescribing skills whereas the rest were not. Prerna et al also obtained similar result regarding first year postgraduate students acknowledgement about prescription writing and rating of CPT. ${ }^{11}$ Kazeen et al also conducted similar study on interns at Nigeria and obtained the similar result. ${ }^{12}$ However majority of them encountered problem during prescription which didn't correlate with previous data and problems mainly were calculation of doses, trade name of drugs and selection of drugs. One study conducted on drug dose calculating skills showed from junior and newly graduated doctors lagging behind in their dosage calculating skills and only half of interns had always double-checked their calculated doses. ${ }^{13}$ Similarly in another study conducted in Nepal suggested that training sessions on dosage calculation to be done at undergraduate level in Pharmacology as well as reinforcement of the same by various clinical departments had been insisted. ${ }^{14}$ Another important drawback at UG level is memorizing doses rather than calculating doses at pediatric level and this leads to more prescription error. So training the undergraduate students on dose calculation and exposure to selection of drugs at clinical side is inevitable. This would prepare them for safe prescription later during their practice. Also majority felt that clinical experience would improve their prescribing ability. But the lacunae at our setup are the enforcement of theoretical knowledge rather than practical teaching at undergraduate level. By exposing them to practical training and reassessment of their talents will bring confidence and practicing skills in them. CPT teaching could be made interesting by group discussion in clinical oriented pharmacology teaching rather than seminar according to one study. ${ }^{15}$

Drugs they managed to prescribe confidently without supervision were antacids, NSAIDS, vitamins and minerals, antihistamines, antibiotics, antiemetics, antiasthmatics, and inhalers; similar results were seen in a study conducted by Rehan et al. ${ }^{16}$ Antibiotics, nonsteroidal anti-inflammatory drugs seem to be common cause of ADR at hospitals and common ADR being gastrointestinal bleeding due to drug therapy. ${ }^{17-19}$ Also the other drugs, where interns mentioned that they were confident to prescribe unsupervised, were also associated with several ADR. ${ }^{20}$ Prescribing errors were common with the interns due to number of factors during internship like lack of drug knowledge, increased workload, poor guidelines and inadequate supervision. ${ }^{21}$ Majority of interns were not confident to prescribe drugs for special categories like elderly, pediatric, pregnant women and patient with systemic illness. Hence more emphasis should be given at undergraduate level at these areas also. Only few were confident to prescribe NSAID and antibiotic. However this confidence seemed to have gained because of repeated usage in clinical posting rather than knowledge about the drug. This also attributes to increasing number of prescription errors. According to majority, safety of patient was considered as prime 
importance whereas few mentioned the need to consider the cost and efficacy of the drug during prescription which is a good lead for rational prescription of drugs.

Almost all were aware of adverse drug reaction. However only half have encountered it during internship in our study. They have documented it as due to drug-drug interaction and majority opined that it led to hospitalization. Unfortunately in spite of majority feeling that ADR was avoidable or predictable, only very few had voluntarily reported it to the concerned Head of the Department and ADR monitoring committee in the hospital. In India Pharmacovigilance programme is initiated by the Central Drugs Standard Control Organization (CDSCO), Directorate General of Health Services under the aegis of Ministry of Health \& Family Welfare, Government of India in collaboration with Indian Pharmacopeia commission, Ghaziabad, which serves as national coordinating centre. This centre works in collaboration with the WHO Collaborating Centre Uppsala Monitoring Centre, Sweden and will be operated under the supervision of a Steering Committee. There are zonal and sub zonal CDSCO offices included under this programme. ADR Monitoring Centres are MCI Approved Medical Colleges \& Hospitals, Private Hospitals, Public Health Programmes and Autonomous Institutes. The goal of this programme is to ensure that the benefits of use of medicine outweigh the risks and thus safeguard the health of the Indian population. Physicians associated with under-reporting of adverse drug reaction had been documented in a study. ${ }^{22}$ Underreporting could be due to reasons like considering ADR reporting as additional burden, avoiding scrutiny of professional competence and insufficient awareness/training. At internship underreporting is mainly due to insufficient awareness about ADR reporting. As todays interns are tomorrow physicians, sound knowledge about the Pharmacovigilance Programme, importance about ADR monitoring and reporting should be educated and improved at undergraduate level.

In our study majority of the interns had the habit of checking the drug profile and the sources were textbooks, CIMS Asia, drug slips and manuals. Even though it was a good lead, the main drawback was interns might prescribe expensive and rare drugs. To overcome this interns and undergraduates must be encouraged to refer National List of Essential Medicines of India. ${ }^{23}$ The World Health Organization had also revised the WHO essential list of medicines for adult and children and referring this list would improve the prescribing ability. ${ }^{24-}$

${ }^{25}$ Considerable number of interns mentioned that drug dosage calculation, pediatric medications, therapeutic drug monitoring, adverse drug reaction, handling of poisoning cases and selection of drugs as the areas where CPT teaching needed to be improved at undergraduate level. All these special areas could be given more importance during undergraduate CPT teaching. However nobody had suggested about the need of pharmacology teaching to be more clinical oriented rather than exam oriented. That is the only way to familiarize them in all the deficient areas. In a study conducted on postgraduates, also suggested teaching prescription writing skills by training students to write dummy prescriptions as a part of undergraduate CPT teaching. ${ }^{10}$

Limitations in our study were inclusion of one batch of interns from one college and assessment of only selfrated confidence of the interns rather than the objective demonstration of prescribing knowledge and skills. Further studies on the same discipline including many colleges and different batches of interns would give a clear picture about CPT teaching in India.

\section{CONCLUSION}

CPT teaching should be improved at undergraduate level for safe rational prescribing, ADR monitoring, reporting and dosage calculation. The educational strategy should include clinical oriented teaching of Pharmacology for undergraduates and periodical assessment of their learning outcomes. Incorporation of Clinical Pharmacology and Therapeutics should also include opportunities to practice prescribing, assessment of prescribing skills and application of national guidance for prescribing.

\section{ACKNOWLEDGEMENTS}

The authors are very grateful to all interns, who participated in the study, for their complete cooperation.

Funding: No funding sources

Conflict of interest: None declared

Ethical approval: Approved by the Institutional Ethical Committee

\section{ANNEXURE 1}

Intern's knowledge of clinical pharmacology and therapeutics at Puducherry- A cross-sectional study

This self-sponsored study is aimed at assessing knowledge of clinical pharmacology and therapeutics (CPT) of interns from Sri Manakula Vinayagar Medical College and Hospital, Pondicherry. Please select the appropriate options and fill-in the blank spaces provided. Ensure all the questions are answered. All the information tendered would be treated with utmost confidentiality.

\section{Demographic data:}

Age:

Gender: M/F

Year:

Posted at present (Department):

When did you finish your final MBBS? 


\section{Questionnaire:}

1. Were you taught CPT in your undergraduate medical course?
(a) Yes
(b) no

2. Do you feel that your undergraduate training equipped you to prescribe safely?
(a) Yes
(b) no

3. How would you rate your knowledge of CPT at present time?
(a) Very poor
(b) poor
(c) Average
(d) good (e) excellent

4. Do you feel that your undergraduate training equipped you to prescribe rationally?
(a) Yes
(b) no

5. Have you encountered any problems while prescribing drugs during your training period?
(a) Yes
(b) no

6. If yes, specify the problems? (Please specify)..................................

7. Do any of the following issues affect your ability to prescribe?
(a) Confidence
(b) Experience
(c) Availability of advice

8. Tick the drugs you prescribe comfortably without supervision? guidance?

(a) antimalarials (b)vitamins and minerals (c) antibiotics (d) NSAIDs (e) antacids and ulcer healing drugs (f) diuretics (g) antihistamines (h) laxatives (i) anti-asthmatics / inhaler (j) Sedatives (k) antiemetics (l) insulin and oral hypoglycaemics (m) vaccines (n) anticonvulsants (o) aminophylline (p) steroids (q) opiate (r) digoxin (s) antidepressants (t) antipsychotics (u) anti-Parkinson's (v) immunosuppressants (w) cytotoxics (x) antihypertensives

9. Which drugs would you be reluctant to prescribe to the elderly, children, pregnant women or people with renal /liver impairment without advice?

(a) antimalarials (b) vitamins and minerals (c) antibiotics (d) NSAIDs (e) antacids and ulcer healing drugs (f) diuretics (g) antihistamines (h) laxatives (i) anti-asthmatics / inhaler (j) Sedatives (k) antiemetics (l) insulin and oral hypoglycemic (m) vaccines (n) anticonvulsants (o) aminophylline (p) steroids (q) opiate (r) digoxin (s) antidepressants (t) antipsychotics $(\mathrm{u})$ anti-Parkinson's (v) immunosuppressants (w) cytotoxics (x) antihypertensives

10. The most important factors to be considered while prescribing a drug?
(a) Safety
(b) efficacy
(c) Cost (d) others (please specify).....

11. Do you know what ADR is?
(a) Yes (b) no

12. Have you seen any ADRs during your training period? (a) Yes (b) no

13. The reason for ADR could be?

(a) Drug-drug interaction (b) medication error (c) idiosyncratic reaction (d) others (please specify).

14. The ADR can result in?

(a) Hospitalization (b) prolongation of hospital stay (c) morbidity (d) death

15. Were the ADRs avoidable/ predictable?
(a) Yes (b) no

16. Could improved training have prevented it?

(a) Yes (b) no

17. Have you ever reported any ADRs?

(a) Yes (b) no

18. If yes, to who have you reported?

(a) ADRs monitoring committee of the hospital

(b) National Pharmacovigilance centre

(c) Head of department (d) others (please specify)....

19. Have you been taught enough at undergraduate level about avoiding ADRs and ensuring patient safety
(a) Yes
(b) no

20. Before prescribing have you ever checked the information about drug that you prescribe?
(a) Yes
(b) no

21. If yes, which materials do you refer? (Please specify)

22. List the topics in CPT where more training is needed (please specify)

\section{REFERENCES}

1. Medical Council of India. Regulations on Graduate Medical Education. New Delhi: 1997.

2. World Health Organization: National Drug Policy and Rational Drug Use. A model curriculum (draft) DAP/85,6. Action programme on essential drugs. Geneva World Health Organization 1985.

3. Dean Bryony, Schachter Mike, Vincent Charles, Barber Nick. Causes of prescribing errors in hospital inpatients: a prospective study. Lancet 2002; 359(9315):1373-8.

4. Bhavsar VH. Experience regarding modification of teaching and the evaluation pattern in practical pharmacology. Indian J Pharmacol 2004;36:385-9.

5. Jaykaran, Chavda N, Yadav P, Kantharia ND. Intern doctors' feedback on teaching methodologies in pharmacology. J Pharmacol Pharmacother 2010;1:114-6.

6. Kuruvilla A, Ramalingam S, Bose Ac, Shastri GV, et al. Use of computer assisted learning as an adjuvant to practical pharmacology teaching: advantages and limitations. Indian $\mathbf{J}$ Pharmacol 2001; 33:272-5.

7. Gitanjali B, Shashindran CH. Curriculum in clinical pharmacology for medical undergraduates of India. Indian J Pharmacol 2006;38:S108-114. 
8. Oshikoya KA, Bello JA, Ayorinde EO. Prescribing knowledge and skills of final year medical students in Nigeria. Indian J Pharmacol 2008;40:251-5.

9. Harding S, Britten N, Bristow D. The performance of junior doctors in applying clinical pharmacology knowledge and prescribing skills to standardized clinical cases. Br J Clin Pharmacol 2010;69(6):598606.

10. Jaykaran, Bhardwaj P, Chavda N, Yadav P, Panwar A. Prescribing knowledge of the intern doctors in India. The Internet Journal of Epidemiology 2009;7:1.

11. Upadhyaya $\mathrm{P}$, Seth $\mathrm{V}$, Sharma $\mathrm{M}$, Ahmed M, Moghe VV, Khan ZY, et al. Prescribing knowledge in the light of undergraduate clinical pharmacology and therapeutics teaching in India: views of first-year postgraduate students. Adv Med Educ Pract 2012;3:47-53.

12. Oshikoya KA, Sebanjo IO, Amole OO. Interns' Knowledge of clinical pharmacology and therapeutics after undergraduate and on-going internship training in Nigeria. BMC Med Educ 2009;9:50.

13. Simpson CM, Keijzers GB, Lind JF. A survey of drug-dose calculation skills of Australian tertiary hospital doctors. Med J Aust 2009;190(3):117-120.

14. Rauniar GP, Das BP, Nagarani MA. Ability to calculate drug dosages. Ind J Pharm 2000;32:129130.

15. Garg A, Rataboli PV, Muchandi K. Students' opinion on the prevailing teaching methods in pharmacology and changes recommended. Indian $\mathbf{J}$ Pharmacol. 2004;36:155-8.

16. Rehan HS, Lal P. Drug prescribing pattern of interns at a government healthcare centre in northern India. Trop Doct 2002;32:4-7.
17. Sriram S, Ghasemi A, Ramasamy R, Devi M, Balasubramanian R, Ravia TK, Sabzghabaee AM. Prevalence of ADRs at a private tertiary care hospital in south India. J Res Med Sci 2011;16(1):16-25.

18. Pouyanne $\mathrm{P}$, Haramburu F, Imbs JL, et al. Admissions to hospital caused by adverse drug reactions: a cross-sectional incidence study: French pharmacovigilance centres. BMJ 2000;320:1036.

19. Pirmohamed M, James S, Meakin S, et al. Adverse drug reactions as cause of admission to hospital: $\begin{array}{llll}\text { prospective analysis of } & 18 \quad 820\end{array}$ patients. BMJ 2004;329:15-9.

20. Jamali AN, Aqil M, Alam MS, Pillai KK, Kapur P. A pharmacovigilance study on patients of bronchial asthma in a teaching hospital. J Pharm Bioallied Sci 2010;2(4):333-6.

21. Coombes ID, Stowasser DA, Coombes JA, Mitchell C. Why do interns make prescribing errors? A qualitative study. Med J Aust 2008;188(2):89-94.

22. Herdeiro MT, Figueiras A, Polónia J, Gestal-Otero JJ. Physicians' attitudes and adverse drug reaction reporting: a case-control study in Portugal. Drug Saf. 2005;28(9):825-33.

23. National List of Essential Medicines of India 2011. Available http://www.cdsco.nic.in/National\%20List\%20of\%2 0Essential\%20final\%20copy.pdf.

24. WHO Model List of Essential Medicines $18^{\text {th }}$ list, April 2013. Available at http://www.who.int/medicines/publications/essential medicines/en/index.html.

25. WHO Model List of Essential Medicines for Children $4^{\text {th }}$ list, April 2013. Available athttp://www.who.int/medicines/publications/essenti almedicines/en/index.html.

doi:10.5455/2319-2003.ijbcp20131020

Cite this article as: Nitya S, Mangaiarkkarasi A, Ali RM, Sawadkar MS. Intern's knowledge of clinical pharmacology and therapeutics at Puducherry: a cross-sectional study. Int J Basic Clin Pharmacol 2013;2:622-8. 